WORKING PAPER \#450

PRINCETON UNIVERSITY

INDUSTRIAL RELATIONS SECTION

JANUARY 2001

http://www.irs.princeton.edu/pubs/working_papers.html

\title{
The Labor Market Consequences of Incarceration
}

\author{
Bruce Western \\ Department of Sociology, Princeton University \\ Jeffrey R. Kling \\ Department of Economics and \\ Woodrow Wilson School, Princeton University
}

David F. Weiman

Russell Sage Foundation

This paper was originally prepared for the Urban Institute's Re-Entry Roundtable, October 12-13, 2000. 


\title{
The Labor Market Consequences of Incarceration
}

\begin{abstract}
Rapid growth in the incarceration rate over the last two decades has made prison time a routine event in the life course of young economically disadvantaged, black and Hispanic men. Although incarceration may now have large effects on economic inequality, only a few studies systematically examine the labor market experiences of ex-offenders. We review the mechanisms that plausibly link incarceration to employment and earnings and discuss the challenges of causal inference for a highly self-selected sample of criminal offenders. There is little consensus about the labor market effects of a variety of justice system sanctions, but there is consistent evidence for the negative effects of prison time on earnings, particularly among older or white-collar offenders. The labor market effects of incarceration are not yet well understood, but prior research suggests several promising avenues for future work.
\end{abstract}

JEL Classification: J4

Keywords: Criminal Offender, Inmate, Employment, Earnings 
The broad facts of U.S. penal population growth are now well known and often recited. Following a seventy-year period in the which the prison incarceration rate remained essentially unchanged, the number of people in state or Federal prison increased from 96 to 468 per 100,000 between 1970 and 1999 (Pastore \& Maguire, 2000, Table 6.26). By 1999, the total prison and jail population numbered 1.86 million (Beck, 2000). Whites have contributed a shrinking share as the penal population has grown in absolute size. Non-Hispanic whites accounted for $42 \%$ of all state prison inmates in 1979, but just 33\% by 1997. Using 1991 data, Bonczar and Beck (1997) estimate that $28.1 \%$ of all black men will spend time in prison at some point in their lives. Not surprisingly, but less well documented, the risk of incarceration also varies substantially by age and education. An estimated $11 \%$ of black males and $4 \%$ of Hispanic males in the their twenties and early thirties were in prison at midyear 1999 (Beck, 2000). Over a third of black male high school dropouts aged 20 to 35 were in prison or jail on average day in the late 1990s - more than the fraction in paid employment (Western \& Pettit, 2000). In sum, historically unprecedented growth in the penal population has been highly concentrated among young, low-skill minority men.

In this paper we review research on the effects of incarceration on the labor market experiences of offenders after they are released. Recent trends in incarceration suggest two significant issues for studying the re-entry of prisoners into the labor market. First, if spending time behind bars seriously damages the employment prospects of criminal offenders, the massive growth in the penal system will have a devastating impact on the economic opportunities of minorities and those with little education. Because prison time has become pervasive among low-skill minority males, a large earnings or employment penalty incurred by incarceration will significantly deepen racial and educational inequality among men. 
Second, incarceration rates have reached astonishing levels at the margins of the labor market among men whose employment prospects are extremely poor, even in the absence of incarceration. While the aggregate effects of the penal system on economic inequality are possibly very large, causal inference about the effect of imprisonment on labor market performance is a difficult scientific problem. Incarceration may not be undermining the economic opportunities of ex-inmates; it may simply be officially earmarking severely disadvantaged men who would otherwise have poor job prospects, although without the dubious distinction of membership in a policy-relevant population. Much of the research on the economic effects of criminal justice system contact has been concerned with this issue. Are the labor market experiences of ex-offenders due to the effects of conviction or incarceration or are they due to characteristics of offenders that simultaneously place them at risk of arrest and low earnings or unemployment?

Our review highlights the endogeneity of incarceration to employment because this has been a central issue in the research literature. However, it is important to note that rapid increase in the incarceration rate has not been driven by underlying behavioral shifts reflected in patterns of criminal offending (Blumstein \& Beck, 1999; Mauer, 1999). Instead, the growth in incarceration appears to have been fuelled by tougher sentences for repeat offenders and drug offenders, and a more punitive approach to post-release supervision. Exogenous shifts in criminal justice policy suggest that the experience of prison time is more than simply an observable marker of an underlying behavioral propensity. Imprisonment is partly a function of policy choice and is not completely reducible to offender behavior. Incarceration effects are, to an important degree, policy effects. In this context, the critical question is whether the new regime of "mass" incarceration reinforces the marginal position of disadvantaged and minority men in the labor 
market and larger political economy through a cycle of diminished employment opportunities, illicit work, and incarceration.

\section{Ex-offenders in the Labor Market}

Three main causal mechanisms link the experience of imprisonment to the risk of unemployment or low earnings. Incarceration is stigmatizing; it may also undermine the acquisition of human and social capital. Some researchers also place these three mechanisms in a life course perspective, in which the timing of incarceration influences its effect. In the current period of mass incarceration, individual incarceration effects may also have larger aggregate-level consequences.

\section{(i) Causal Mechanisms}

The negative relationship between crime and employment is often attributed to the stigma of criminal conviction. Early research argued that criminal conviction signaled convicts' untrustworthiness (Schwartz \& Skolnick, 1962). Evidence for the stigma of conviction was provided by experiments in which employers were sent fictitious letters of job application containing information about the conviction status of job applicants (Boshier \& Johnson, 1974; Buikhuisen \& Dijksterhuis, 1971). Employers were less likely to respond positively to exconvicts than those who provided no information about past convictions. Recent survey data similarly suggest that employers would be more likely to hire welfare recipients or applicants with little work experience than ex-convicts (Holzer, 1996, p. 59). 
In most jurisdictions, the stigma of conviction takes on a legal significance. Commonly, a felony record can temporarily disqualify employment in licensed or professional occupations. These prohibitions typically extend beyond the professions to include jobs in health care and skilled trades. Additionally felony status in several states can bar public sector employment. The severity of civil disabilities varies across states. In Florida, for example, felony conviction creates a permanent disability that can be removed only by application to the state clemency board. Although the legal status of ex-felons is well documented (Office of the Pardon Attorney, 1996), little is known about the effects on employment of civil disabilities.

Incarceration may also erode the job skills of ex-inmates. While social stigma describes employers' perceptions of those with criminal records, the erosion of human capital refers to real deficiencies in the productivity of ex-inmates as a consequence of their imprisonment. Incarceration may undermine the acquisition of job skills among ex-inmates in comparison to others who remain continuously employed (Waldfogel, 1994). More than this, time in prison may exacerbate pre-existing mental or physical illnesses. In addition, behaviors that are adaptive for survival in prison are likely to be inconsistent with work routines outside (Irwin \& Austin, 1997, p. 121). These effects may be especially large in the recent period as support has declined for training, drug treatment and health care. Although anecdotal reports of these effects are striking there is remarkably little research (outside the field of program evaluation) that links inmates' experience of prison or jail to their experiences in the labor market after release. Obtaining such information is an important research priority in trying to understand the effects of incarceration on employment and earnings. 
Incarceration may affect social, as well as human, capital. A large proportion of jobs are found through personal connections that match workers to employers (Granovetter, 1995). The social contacts that provide information about job opportunities may be weakened as a result of incarceration. Hagan (1993) argues that juvenile delinquency embeds young offenders in social contexts with weak connections to stable employment opportunities. If prisons are themselves criminogenic, incarceration may have a similar negative effect on job referral networks. In this scenario, inmates build social connections to those promoting opportunities for further criminal activity after release, and social ties to legitimate employment are weakened.

(ii) Incarceration and the Life Course

A life course perspective has tried to place these mechanisms in the context of key transitions traversed by adolescents on the way to adulthood. Longitudinal perspectives on crime and earnings share the argument that individual outcomes at a point in time represent just one piece of a longer trajectory of employment or criminal behavior (Bernhardt, Morris, Handcock, and Scott, 1998; Sampson \& Laub, 1993). Typically, young male full-time workers enjoy strong earnings growth through their twenties and thirties. The acquisition of firm-specific-human capital, internal labor markets in large firms, public sector pay schedules, and union seniority provisions ensure job continuity and earnings growth for young men (Spilerman, 1977). Consequently, earnings rise strongly with age in primary sector jobs.

The punctuating effect of incarceration on the life course is associated most prominently with the work of Sampson and Laub $(1993,1997)$. They argue that that early incarceration can contribute to an accumulation of disadvantage, often beginning with juvenile delinquency that "may spark failure in school, incarceration and weak bonds to the labor market, in turn 
increasing later adult crime" (Sampson \& Laub 1993, 1997, p. 144). This argument suggests that incarceration can interrupt young men's transition to stable career employment (Nagin \&Waldfogel, 1998; Western, 2000). The inaccessibility of career jobs to ex-inmates can be explained in several ways. The stigma of incarceration makes ex-inmates unattractive for entrylevel or union jobs that may require high levels of trust. In addition, civil disabilities limit exfelons access to career employment in skilled trades or the public sector (Office of the Pardon Attorney, 1996). Employers may be unwilling to invest in the firm-specific skills of workers with criminal records. Ex-offenders are then relegated to spot markets with little prospect for earnings growth (Nagin \& Waldfogel, 1998). Entry to trades and public sector employment also depends strongly on referral networks (Granovetter, 1995, pp. 173-74). To the extent that incarceration undermines social networks, ex-inmates will have limited access to apprenticeships and careers in crafts and the public sector. In sum, the incarceration of young men disrupts entry into stable career jobs with strong earnings growth. Consequently, many ex- inmates find work in casual or illegitimate employment in the secondary labor market (Sullivan, 1989).

\section{(iii) Agglomeration Effects}

While most of the research reviewed so far suggests emphasizes the individual level effects, another strand of research recognizes the potential cumulative impacts from the massive flows of offenders into and out of jails and prisons. Although sketchy, evidence suggests the spatial concentration of released prisoners in inner city and surrounding suburban communities (Sabol \& Lynch, 1998; Rose \& Clear 1998). Almost three-fourths of the New York state prison population come from seven New York City neighborhoods, and Baltimore accounts for more than half of the prison population in Maryland. Likely to return to their home communities, the 
numbers of released prisoners will mount over time, and a prison record will become an increasingly ubiquitous characteristic, especially for groups most affected by this criminal justice policy. Given the high cumulative risks of imprisonment among black men in general (Bonczar \& Beck, 1997) and extraordinary point-in-time incarceration rates among young drop outs (Western \& Pettit, 2000), a clear majority of black high school drop outs are likely to have been to prison at some time.

The spatial concentration of incarceration can potentially compound the barriers to meaningful employment for released prisoners and their peers. The sheer volume of individuals moving into and out of prison can dramatically alter the conditions of supply and demand in local labor markets. As Western and Becket (1999) imply, the immediate impact of withdrawal or incapacitation may reduce labor supplies and so improve prospects for those left behind. But upon their return, they will augment the supplies of disadvantaged workers, confined to secondary labor markets, and so have the opposite effect. Over longer periods of time, moreover, the concentration of released prisoners in the local population could affect firms' locational decisions and so reduce labor demands.

The cumulative flows of released prisoners will also alter their social networks and norms outside of prison, and so reinforce their limited attachment to the legitimate labor market. Upon their return, released prisoners can readily reestablish contacts formed in prison and so embed themselves in networks of other released prisoners. These ties can erode the social stigma of a criminal conviction and incarceration. Moreover, it further weakens connections to those who can provide information about and entry to job openings. These concentration effects, in turn, can tarnish others in their community through the formation of stereotypes by statistical discrimination or racial profiling. 


\section{Identifying and Measuring the Effects of Incarceration}

In order to assess the total social costs and benefits of different incarceration policy alternatives on labor market outcomes, the most basic information we need is about the size of these effects. Are they large or small? For a full assessment, we would need to consider the direct effects on offenders, and also the indirect effects. An indirect effect on health, for example, would be difficulty in finding employment that may result in mental health problems such as depression. There are also indirect impacts on children and other family members, such as through reduced financial support via legitimate income sources. While we recognize the importance of indirect effects, most are beyond the scope of this paper.

\section{(i) Identifying Causal Effects}

In studying the effect of incarceration on labor market outcomes, there are several different incarceration policy instruments of potential interest. We begin by considering a group of individuals convicted of crimes. One instrument may be serving time in prison (in comparison to some alternative sentence, perhaps involving fines, community service, treatment, and/or supervision in the community). Another policy instrument may be the length of time spent in prison (say, one year versus two years).

A variety of labor market outcomes may also be of interest. Is an individual employed in the mainstream economy at some point in time after conviction? What are the usual hours and hourly wage? How long did it take to find the first job after release? What proportion of time has been spent employed since release? How do earnings compare to earnings prior to conviction? How have earnings changed over time after conviction? 
For any well-posed question, such as "What is the causal effect of increasing the length of a prison term from one year to two years on employment rates five years after conviction?", we can consider the answer for a variety of population subgroups. Effects may differ according to age, gender, race, ethnicity, education, work experience, and prior criminal record. Effects may also differ across geographic areas and across time, perhaps because of local labor market conditions. Understanding how effects differ across groups is particularly important for assessing whether particular groups are especially affected and may help target policy responses. For example, if older offenders experience larger negative effects of incarceration than younger offenders, there may be more potential for education and rehabilitative programs targeted to older offenders to offset such negative effects.

The fundamental challenge in measuring the magnitude of the effect of incarceration is identification of the causal effect of incarceration itself. For assessing the impact of an additional year in prison, simple comparisons between those serving one or two years may be biased if the group serving two years is systematically different than the group serving one year. One way to see this directly would be to observe that those serving two year prison terms tended to have lower employment rates prior to conviction than those serving one year. This would suggest that those serving two-year terms would have had worse subsequent labor market outcomes even if they had served only one year.

A longstanding criminological interest in the effect of employment on crime and incarceration suggests that the self-selection of offenders into prison creates severe difficulties for causal inference. Just as those with low self-control are at a high risk of committing crime, "people with low self-control will [also] have difficulty meeting the obligations of structured employment" (Gottfredson \& Hirschi, 1990, p. 165). Psychologists make similar arguments 
about men exhibiting persistent anti-social behavior. Persistent anti-social behavior is rooted in neuro-psychological deficits that influence the risk of official crime and irregular employment (Caspi, Wright, Moffit \& Silva, 1998; Moffit, 1993).

There are several ways to solve this identification problem. One way is to collect very rich data on observable factors, including labor market histories, and only make comparisons between individuals that are otherwise similar but differ in prison sentence length. Methodological research in other contexts has shown that this approach, sometimes called "selection on observables", can come close to replicating randomized trials. Theories of self-control and antisocial behavior suggest control variables that can account for low productivity and inmate selfselection. Thus researchers have controlled for histories of anti-social behavior, cognitive ability, and measures of impulsivity or aggressivity, in trying to isolate the causal effects of incarceration on subsequent experiences in the labor market (Freeman, 1992; Hagan, 1993; Caspi et al., 1998).

It can also be very helpful to limit comparisons to individuals in the same labor market at the same point in time. As famously demonstrated by Lalonde (1986), using a population random sample to form the control group for an unusual population (in his case, trainees who had suffered economic and social problems, including some arrestees) turned out to lead to very poor causal inference. More recently, Dehejia and Wahba (1999) and Heckman, Ichimura, Smith, and Todd (1998) have demonstrated through use of statistical methods based on the propensity score that it is extremely useful to base statistical comparisons only on those who are observably similar to the group of interest, and that these comparisons generate similar results to a demonstration program that randomly assigned training to some applicants. 
Another approach relies on quasi-experiments that may affect sentence length for otherwise similar groups. For example, it could be the case that changes in sentencing guidelines are implemented in such a way that individuals arrested before a particular date are under one regime, while individuals arrested after that date are under another regime with longer sentences. Comparisons between the two groups could identify the effect of sentence length on later outcomes. It would be helpful to examine another group in that same labor market, such as unskilled minority men, in order to assess whether there were important changes over time (before and after the guidelines) that might need to be modeled if confounded with the simple difference before and after guidelines implementation.

\section{(ii) Estimates of Incarceration Effects}

To date, there have been three main types of research designs used to study the effects of incarceration on labor market outcomes. The first type of design has used survey data to compare those in jail to those not in jail in terms of their subsequent labor market outcomes. For example, Freeman (1992) used the NBER Boston Youth Survey and the National Longitudinal Survey of Youth 1979 cohort (NLSY79). Of these two data sources, the NLSY79 had somewhat richer data on previous labor market history, and could examine longer-term labor market outcomes (4-7 years after being observed in jail). Both analyses showed that youth who had been in jail had substantially fewer weeks worked. The NLSY79 also showed employment rates were 15-25 percentage points lower for those who had been jailed. More recently, Western and Beckett (1999) have used the NLSY79 data to study the dynamics of labor supply after confinement, and show that the juvenile incarceration is associated with a small but persistent decrease in weeks worked after seven years. 
The second main research design has used employment data gathered by probation officers of federal offenders before and after release. Lott (1992a) finds no significant relationship between prison sentence length and the change in income before and after conviction for drug offenders. Lott (1992b) finds very large effects of prison sentence length on earnings for fraud and embezzlement offenders, where a one month increase in sentence length is associated with a decline of 5.5 to 32 percent lower income, depending upon the specification. Waldfogel (1994) uses the panel nature of the data to study the difference between income before and after conviction for fraud and larceny offenders. He finds that those who were imprisoned have later employment rates 5-12 percentage points lower, and income 16-28\% lower than those convicted who did not go to prison.

Use of administrative records on earnings collected through the Unemployment Insurance (UI) system has led to a third main type of research design. For example, Grogger (1995) used UI records from California to track the labor market outcomes of individuals serving jail terms (up to one year). Eighteen months after the jail term began, Grogger found that employment rates were about four percentage points lower, from an overall sample mean of 0.54. Notably, for other criminal justice events such as arrest and conviction, there was essentially no estimated effect after eighteen months. A study of longer term outcomes was undertaken by Needels (1996), using UI data from Georgia. She examined the percentage of time offenders were incarcerated from 1976-1983 on their subsequent employment, and found no significant effect. For earnings, however, she found that an additional year of incarceration reduced total earnings from 1983-91 by about 12 percent. 
Kling (1999) uses UI data on employment and earnings of federal offenders in California, focusing on the effects of serving any time in prison and of the length of time served on longterm labor market outcomes. The results show that incarceration has surprisingly little effect on employment in comparison to those who are not incarcerated, with employment rates only 0-3\% lower after 5 to 8 years for those who served prison time. Further, employment rates for those with longer sentences rebound just as quickly to pre-conviction levels as do those with similar characteristics but shorter sentences. Negative earnings effects are more pronounced and are concentrated among white-collar criminals, who earn 10-30\% less after 5 to 8 years than those who were convicted at the same time but not incarcerated. Violent and drug offenders have very low earnings in the legitimate sector overall, but these earnings appear to increase over the longterm after release from prison and do not vary with the length of time served.

How do these research findings shed light on the proposed mechanisms connecting incarceration to employment and earnings? Of course, the finding of a negative incarceration effect on earnings or employment is consistent with stigma, human and social capital mechanisms. Evidence for one mechanism over another has been taken from studies distinguishing different types of offenders and criminal justice system contact. Waldfogel (1994) finds that Federal fraud and larceny offenders engaging in a breach of trust in their occupation suffer a 5 to 12 percentage point decline in the probability of employment after conviction, surpassing the employment loss experienced by other offenders who have not breached trust. This pattern supports the influence of the stigma of conviction. Analysis of the same data also shows a relatively large earnings loss for offenders with college education. Along similar lines, Lott (1990) finds that the decline in income after conviction in a sample of Federal offenders is largest for those with highest pre-conviction incomes. The large effects in this research also 
indicate the effects of social stigma because criminal conviction is likely to be more stigmatizing for high-status offenders.

If stigma attaching to criminal justice contact reduces earnings or employment, we might expect little difference in the effects of arrest, conviction, probation, or incarceration. From the employer's viewpoint, each intervention carries similar information about the trustworthiness of a prospective worker. Some work has distinguished the effects of juvenile delinquency from arrest, probation, and adult incarceration (Freeman, 1992; Grogger, 1995; Western \& Beckett 1999). Incarceration effects are relatively large for this research, suggesting that other mechanisms in addition to stigma might be operating. Grogger (1995), for instance, estimates separate effects for arrest, conviction, probation, jail and prison time. Prison time incapacitates the offender from employment in the open labor market, preventing the acquisition of work experience. Prison is found to have an especially large and persistent negative effect on earnings, suggesting the impact of prison on the erosion of job skills (Waldfogel 1994 reports similar results).

Is there evidence for the impact of incarceration on social networks? Although there is little quantitative evidence for this effect, ethnographic findings are suggestive. Sanchez Jankowski (1991, pp. 272-76) reports that incarceration can deepen inmates' attachments to gangs (see also Venkatesh, 2000, p. 133). More generally, urban ethnographers report that inner-city youth become enmeshed in peer networks that connect frequently with the criminal justice system, but rarely with opportunities for stable employment (Sullivan 1989). Although quantitative analysis has not studied the impact of imprisonment on social ties to employment, the disruptive impact of imprisonment on social capital has also been found in family relationships. In analysis of a survey of new parents, Western and McLanahan (2000) found that ex-inmates shared a low 
likelihood of marriage or cohabitation. Laub, Nagin, and Sampson (1998) similarly report that chronic offenders are at high risk of separation and divorce.

Incarceration effects also appear to vary over the life course. Life course effects have recently been highlighted in studies of criminal desistance (Bushway \& Reuter, 2001). Just as program effects appear to increase with age, the negative effects of prison time on employment and earnings also appear to be concentrated among older offenders. Nagin and Waldfogel's (1998) analysis of federal offenders finds that the negative effect of criminal conviction on income is restricted to those over age 30. Western's (2000) analysis of the NLSY shows that the age-earnings profile of ex-inmates is flat in contrast to the strong earnings growth enjoyed by young men who have never been incarcerated. Thus the earnings gap between non-inmates and ex-inmates grows with age.

(iii) Policy Impacts

Policies aimed at improving the labor market outcomes of ex-offenders implicitly assume that later outcomes of individuals can be affected by the policy. In the 1970s, this rehabilitative view fell out of favor, due in part to the famous literature review by Martinson (1974), which noted: "With few and isolated exceptions, the rehabilitative efforts that have been reported so far have had no appreciable effect on recidivism" (p. 25). McDonald (1998) and Bushway and Reuter (1997) review the literature since then on programs and their impacts on labor market outcomes. Here we discuss selected examples of the methodologically strongest studies.

Two studies using randomized research designs undertaken after Martinson’s review also showed essentially no impact. The Transitional Aid Research Project (TARP) experiments in Georgia and Texas were designed to test the hypothesis that limited financial assistance after 
release from prison could lower the rates of property crime committed by released prisoners (Rossi, Berk, \& Lenihan, 1980). After analysis comparing randomly assigned groups, the results indicated that TARP payments did not reduce recidivism. Hours of work were lower in the year after release for those receiving assistance, although there was no decrease in total earnings indicating that those receiving assistance were able to use the financial assistance to more effectively search for higher wage jobs to offset their lower work hours.

Another randomized evaluation was undertaken of the National Supported Work demonstration, which provided a 12-18 month closely supervised employment opportunity for ex-offenders. Effects on employment and earnings three years after random assignment were positive but substantively small and statistically insignificant; effects on recidivism were similarly insignificant (Piliavan \& Gartner, 1984). Recent re-analysis of these data by Uggen (2000) however finds that among offenders over age 27, the proportion reporting illegal earnings is about $7 \%$ lower for the program group than the control group. This finding raises the possibility that program effects may depend on the offender's age.

More recent evidence also provides evidence for program effects. Two of the better studies, while not using random assignment, have attempted to construct comparison groups of nonparticipants against which to gauge the effects of the interventions. Project RIO in Texas is an intervention designed to provide job preparation and job search assistance to released prisoners. Regressions controlling for education, age, and race find that participants worked an additional 0.22 quarters per year in the short term (Menon et al., 1992). A study of federal prisoners who participated in academic, vocational and work experience programming (PREP) used a much more extensive set of variables and more sophisticated statistical matching techniques to create an observationally similar comparison group. Twelve months after release, Saylor and Gaes 
(1997) report that 72 percent of program participants were employed, versus $63 \%$ of those in the comparison group, and one-year recidivism was also lower.

\section{Research Designs and Future Research}

Previous nonexperimental research and program evaluation, although inconclusive, provide several important lessons in research design. A strong research design must generate data with three related characteristics. First, the design must yield data that will help identify an incarceration effect. Second, information about the conditions of confinement should be available for analysis. Third, the design must take special steps to ensure that the labor market experiences of re-entering inmates are completely observed. These general design characteristics have a number of concrete implications for future research.

To identify an incarceration effect, we need information about imprisonment that is unrelated to behavioral characteristics that influence labor market performance and the likelihood of criminal conviction. A number of designs try to provide this information by observing labor market experiences before and after incarceration. With this information, the change in earnings or employment observed after release is plausibly due to imprisonment and not enduring behavioral characteristics of offenders. A similar approach involves collecting data from a control group - say convicted but noncustodial offenders - who are similar to inmates in key respects except for incarceration. Survey research has also collected detailed behavioral information. Measures of cognitive ability, self-control, or a history of delinquency, can all help to isolate statistically the experience of incarceration from its behavioral covariates. Variation in the sentencing process - changes in sentencing rules or the sentencing behavior of judges, for example - also helps identify that component of the incarceration experience that is independent 
of offender behavior. A research design featuring pre-incarceration observation, behavioral covariates, or sentencing information provides some leverage in making a causal inference about the labor market effect of incarceration.

Information about imprisonment can also be provided by data on the conditions of confinement. Program evaluation sensitizes us to the fact that the experience of imprisonment can vary greatly across institutions. Still, outside of the evaluation field, prisons and jails are black boxes. Offenders enter correctional facilities and are later released, but the actual content of the incarceration treatment is usually unobserved. Participation in prison programs, health services, characteristics of the surrounding inmate population, crowding and other conditions of confinement may all influence post-release experiences. To the extent that these institutional characteristics are exogenous features of the penal system, unrelated to offender characteristics, data on the conditions of confinement can assist in the identification of causal effects. More than this, information about the experience of imprisonment can also shed light on the mechanisms linking incarceration to poor employment opportunities. For instance, ex-inmates may do reasonably well on the labor market if they complete job-training programs. If few inmates complete such programs, low earnings and unemployment among ex-inmates may be rooted in human capital deficits. (Of course inference, this kind of inference is also subject to concerns about the self-selection of inmates into programs.) Subsequent analysis can go much further to include information about the experience of imprisonment in explaining variation in post-release experiences.

Finally, men with prison or jail records are an extremely hard population to systematically observe. They are often engaged in economic activity at the margins of the formal economy. In many cases, such men are not strongly attached to households and would not 
routinely be covered by traditional sampling methods. Consequently the two main data sources for studying ex-inmates - survey data and administrative data -- may be subject to severe nonresponse bias. Evidence for this bias in administrative data is provided by large discrepancies between the earnings of young male ex-offenders in UI data and self-reported in earnings in surveys (Kornfeld \& Bloom, 1999). In the NLSY, the main survey data source on the effect of incarceration, survey attrition is strongly related to prior delinquency and imprisonment. The deficiencies of survey and administrative data suggest several directions for improving research design. In the analysis of administrative records, some kind of data validation would be useful. For example, comparison with self-reported job histories (gathered longitudinally or retrospectively) would allow assessment of whether higher earnings from self-reports were due to differences in the number of employers with administrative data on earnings or in the level of earnings from a particular employer. Survey researchers might profitably interview other informants, perhaps mothers or spouses, who are more firmly attached to established households. This strategy may reduce bias to due to survey nonresponse. Missing data problems have not been studied closely in research on prisoner re-entry. However, there are indications these problems are severe and the quality of data for studying ex-inmates has been poor. To advance existing knowledge about the post-release experiences of ex-inmates, new data collections must treat systematic nonresponse as a central methodological problem.

What are the concrete implications of this brief discussion for future research? Administrative data and social surveys remain the two main alternative data sources for studying the labor market effects of incarceration. Matched correctional and UI records continue to offer the possibility of very large samples at low cost. In light of recent research on life course effects, the lengthy time series provided by administrative data would seem to offer valuable new 
research opportunities. Given the limits of previous research, however, future work could go further by incorporating information about correctional facilities or program participation. Evaluations of the quality UI earnings and employment data on ex-inmates are also urgently needed.

Survey analysis is much more expensive than collecting administrative data yet survey data may provide better labor market information and a wider range of a behavioral covariates. Do the advantages of survey research design outweigh the costs? Unfortunately, too little is known about the relative quality of survey and administrative data to provide an informed answer to this question. Intermediate solutions that help us evaluate the quality of survey data are available, however. Small-area surveys in high crime neighborhoods or small-scale surveys of offenders could offer more information at intermediate cost. Because exogenous shifts in sentencing policy appear to have increased the incarceration risk among low-level non-violent offenders (Blumstein \& Beck, 1999), the exogenous impact of incarceration may best be observed here - among small-time drug offenders and other street criminals. These marginal offenders who would not have been imprisoned under a less-punitive sentencing regime, may thus offer a critical population for observing incarceration effects. Sampling efforts focused on these offenders may offer reasonable potential for survey analysis of the effects of incarceration.

\section{Conclusion}

Based on our review of recent literatures, we find evidence from a variety of sources that a serving time in prison can diminish an individual's earnings, but not necessarily employment, prospects (see for example Grogger, 1995; Nagin \& Waldfogel 1998; Western \& Beckett 1999; Kling, 1999; and Western, 2000). What's more, these negative impacts appear to be greater for 
older individuals, especially those with white-collar occupations. Estimates from the survey and administrative data suggest that the earnings penalty of imprisonment ranges from 10 to 30 percent. By contrast, the evidence on employment and earnings penalties from arrest, conviction, and time in jail is uneven. Additionally, with existing data sources, we cannot precisely measure the differential impacts of arrest, conviction, and incarceration by demographic or racial-ethnic group or infer the underlying causal mechanisms, including the agglomeration effects from the spatial concentration of released prisoners.

Studying the effects of contact with the criminal justice system is a hard scientific problem. This is reflected in the unevenness of prior research findings. Criminal offenders are a highly self-selected group. They move in and out of institutional settings, crossing boundaries that usually organize the division of labor in traditional social research. Their economic activity often falls within a gray area that escapes detection by the criminal justice system and social insurance agencies. Their housing and patterns of household attachment often place them out of the reach of traditional social survey methods.

Although we have much to learn about the experience of ex-inmates in the labor market, prior research offers important clues about strengthening research design. Data collection efforts must be broadened, to isolate that part of the incarceration experience that is unrelated to characteristics that produce low earnings or a high risk of unemployment. Data collection must also strive to ensure that nonresponse is minimized. This may involve departing from traditional methods of administrative or survey data collection.

Historically, the large gaps in our knowledge about prisoner re-entry were of little consequence. Inmates were a small idiosyncratic population with little macro-social significance. Today, incarceration is pervasive among disadvantaged black and Hispanic men. Understanding 
the labor market experiences of ex-inmates may thus be central to understanding contemporary patterns of race and class inequality, and the social problems of inner cities. Research on the economic fortunes of ex-inmates is thus a key research priority. 


\section{REFERENCES}

Beck, A. J. (2000). Prison and Jail Inmates at Midyear 1999. Bureau of Justice Statistics Bulletin. NCJ 181643.

Bernhardt, A., Morris, M., Handcock,, M. \& Scott, M. (1998). "Inequality and Mobility: Trends in Wage Growth for Young Adults." Institute on Education and the Economy Working Paper No. 7. New York: Columbia University.

Blumstein, Alfred and Allen J. Beck. (1999). "Population Growth in U.S. Prisons, 19801996." Pp. 17-62 in Crime and Justice: Prisons, vol. 26, edited by Michael Tonry and Joan Petersilia. Chicago: University of Chicago Press.

Bonczar, T. P. \& Beck, A. J. (1997). Lifetime Likelihood of Going to State or Federal Prison. Bureau of Justice Statistics Special Report. NCJ 160092.

Boshier, R. \& Johnson, D. (1974). "Does Conviction Affect Employment Opportunities?" British Journal of Criminology, 14:264-268.

Buikhuisen, W. \& Fokke P.H. Dijksterhuis. (1971). "Delinquency and Stigmatisation." British Journal of Criminology, 11:185-187.

Bushway, S. D. \& Reuter, P. (1997). "Labor Markets and Crime Risk Factors." In Lawrence W. Sherman et al., Preventing Crime: What Works, What Doesn't, What's Promising. http://www.ncjrs.org/works.

Bushway, S. D. and Reuter, P. (2001). "Labor Markets and Crime.” In Joan Petersilia \& James Wilson (Eds.), Crime ( ${ }^{\text {rd }}$ ed.). San Francisco: ICS Press.

Caspi, A., Wright, B. R. E., Moffit, T. E. \& Silva, P. A. (1998). "Early Failure in the Labor Market: Childhood and Adolescent Predictors of Unemployment in the Transition to Adulthood." American Sociological Review, 63:424-51.

Dehjia, R. H. \& Wahba, S. (1999). "Causal Effects in Nonexperimental Studies: Reevaluating the Evaluation of Training Programs." Journal of the American Statistical Association, 94:1053-1062.

Freeman, R. B. (1992). "Crime and the Employment of Disadvantaged Youth.” Pp. 201-37 in George Peterson \& Wayne Vroman_(Eds.), Urban Labor Markets and Job Opportunity. Washington DC: Urban Institute Press.

Gottfredson, M. R. \& Hirschi, T. (1990). A General Theory of Crime. Stanford, CA: Stanford University Press. 
Granovetter, Mark. (1995). Getting a Job: A study of Contracts and Careers. ( $2^{\text {nd }}$ ed.). Chicago: University of Chicago Press.

Grogger, J. (1995). "The Effect of Arrests on the Employment and Earnings of Young Men." Quarterly Journal of Economics, 110:51-71.

Hagan, John. (1993). "The Social Embeddedness of Crime and Unemployment." Criminology, 31:465-91.

Heckman, J. J., Ichimura, H., Smith, J. \& Todd, P. (1998). "Characterizing Selection Bias Using Experimental Data.” Econometrica, 66:1017-1098.

Holzer, H. J. (1996). What Employers Want: Job Prospects for Less-Educated Workers. New York: Russell Sage Foundation

Irwin, J. \& Austin, J. (1997). It's About Time: America's Imprisonment Binge. Second Edition. Belmont, CA: Wadsworth.

Kling, J.R. (1999). "The Effect of Prison Sentence Length on the Subsequent Employment and Earnings of Criminal Defendants." Woodrow Wilson School Discussion Papers in Economics no. 208. Princeton, NJ: Princeton University.

Kornfeld, Robert and Howard S. Bloom. (1999). "Measuring Program Impacts on Earnings and Employment: Do Unemployment Insurance Wage Reports from Employers Agree with Surveys of Individuals?"” Journal of Labor Economics, 17:168-197.

Lalonde, R. J. (1986). "Evaluating the Econometric Evaluations of Training Programs." American Economic Review, 76:604-620.

Laub, John H., Daniel S. Nagin, and Robert J. Sampson. (1998). "Trajectories of Change in Criminal Offending: Good Marriages and Desistance Process.” American Sociological Review, 63:225--38.

Lott, J. R. (1990). "The Effect of Conviction on the Legitimate Income of Criminals." Economics Letters, 34:381-385.

Lott, J. R. (1992a). "Do We Punish High Income Criminals Too Heavily?” Economic Inquiry. 30:583-608.

Lott, John R. (1992b). “An Attempt at Measuring The Total Monetary Penalty From Drug Convictions: The Importance of and Individual's Reputation.” Journal of Legal Studies, 21:159187.

Martinson, Robert. (1974). "What Works-Questions and Answers About Prison Reform," The Public Interest, 22-45. 
Mauer, M.. (1999). Race to Incarcerate. New York: New Press.

McDonald, Douglas C. (1998). "Offender Employment and Training Programs: A Review of the Research.” Pp. 233-250 in Successful Community Sanctions and Services for Special Offenders, edited by Barbara J. Auerbach \& Thomas Castellano. Lanham, MD: American Correctional Association.

Menon, Ramdas et al. (unpublished / 1992?). An Evaluation of Project RIO Outcomes. Public Policy Resources Laboratory, Texas A\&M University.

Moffit, Terrie. E. (1993). "Adolescence-Limited and Life-Course-Persistent Antisocial Behavior: A developmental Taxonomy.” Psychological Review 100:674-701.

Nagin, Daniel \& Joel Waldfogel. (1998). "The Effect of Conviction on Income Through the Life Cycle.” International Review of Law and Economics 18:25-40.

Needels, Karen E. (1996). "Go Directly to Jail and Do Not Collect? A Long-Term Study of Recidivism, Employment, and Earnings Patterns among Prison Releases." Journal of Research in Crime and Delinquency, 33:471-96.

Office of the Pardon Attorney. (1996). Civil Disabilities of Convicted Felons: A State-byState Survey. Washington, DC: U.S. Department of Justice.

Pastore, Ann L. \& Kathleen Maguire. (2000). Sourcebook of Criminal Justice Statistics [Online]. Available: http://www.albany.edu/sourcebook

Piliavan, Irving \& Rosemary Gartner. (1984). "The Impacts of Supported Work on Exoffenders." In Robinson G. Hollister et al. (Eds.), The National Supported Work Demonstration. Madison: University of Wisconsin Press.

Rose, Dina \& Todd Clear. (1998). "Incarceration, social capital, and crime: implications for social disorganization theory." Criminology, 36:441-480.

Rossi, Peter H., Richard A Berk, \& Kenneth Lenihan. (1980). Money, Work, and Crime. New York: Academic Press.

Sabol, William J. and James P. Lynch. (1998). "Assessing the Longer-run Consequences of Incarceration: Effects on Families and Employment." Paper prepared for the 20th annual research conference of the Association for Public Policy and Management. New York.

Sampson, Robert J. \& John H. Laub. (1993). Crime in the Making: Pathways and Turning Points Through Life. Cambridge, MA: Harvard University Press.

Sampson, Robert J. \& John H. Laub. (1997). "A Life-Course Theory of Cumulative Disadvantage and the Stability of Delinquency." Advances in Criminological Theory, 7: 133-61. 
Sanchez Jankowski, Martin. (1991). Islands in the Street: Gangs and American Urban Society. Berkeley: University of California Press.

Saylor, Willam G., \& Gerald G. Gaes. (1997). "Training Inmates through Industrial Work Participation and Vocational and Apprenticeship Instruction." Corrections Management Quarterly, 1:32-43.

Schwartz, R.D. \& J.H. Skolnick. (1962). “Two Studies of Legal Stigma.” Social Problems, 10:133-42.

Spilerman, Seymour. (1977). "Careers, Labor Market Structure, and Socioeconomic Achievement." American Journal of Sociology, 83:551-93.

Sullivan, Mercer. (1989). "Getting Paid:" Youth Crime and Work in the Inner City. Ithaca, NY: Cornell University Press.

Uggen, Christopher. (2000). "Work as a Turning Point in the Life Course of Criminals: A Duration Model of Age, Employment and Recidivism." American Sociological Review, 65:52946.

Venkatesh, Sudhir Alladi. (2000). American Project: The Rise and Fall of a Modern Ghetto. Cambridge, MA: Harvard University Press.

Waldfogel, Joel. (1994). "The Effect of Criminal Conviction on Income and the Trust Reposed in the Workmen."' Journal of Human Resources, 29:62-81.

Western, Bruce \& Katherine Beckett. (1999). "How Unregulated is the U.S. Labor Market: The Penal System as a Labor Market Institution." American Journal of Sociology, 104:1030-60.

Western, Bruce \& Becky Pettit. (2000). “'Incarceration and Racial Inequality in Men's Employment." Industrial and Labor Relations Review, 54:3-16.

Western, Bruce \& Sara McLanahan. (2000). “Fathers in Fragile Families: The Impact of Incarceration on Family Formation." In Families and Crime, edited by Greer Litton Fox. London: Oxford University Press.

Western, Bruce. (2000). “The Impact of Incarceration on Earnings and Inequality.” Paper presented at the annual meetings of the American Sociological Association. Washington, DC. 